\title{
Sustainable environmental development of Karelia and its municipalities
}

\author{
Pavel Druzhinin ${ }^{1}$, Galina Shkiperova ${ }^{1}$, Olga Potasheva ${ }^{1,{ }^{*}}$ \\ ${ }^{1}$ Institute of Economics of Karelian Research Centre of the RAS, 185030, Petrozavodsk, Russia
}

\begin{abstract}
The paper deals with the problems of environmental economics and discusses the impact of economic development on the environment in the Republic of Karelia and its municipalities using the example of pointsource pollutant emissions. The models are built, the calculations are carried out to explain the improvement of an ecological situation with a growth of economy. It is shown that environmental performance in the Republic of Karelia and its municipalities is continuously improving, although the level of pollution per unit of output in municipalities varies greatly. The factors that determine the dynamics of pollution almost coincide, but the extent of their influence is different. The study made it possible to explain the improvement of ecological indicators with economic growth, to identify the factors leading to the improvement of the environment. Structural changes of economic development are important for Petrozavodsk, and investments in environmental protection are important for industrial centres. The growth of investments in active modernization of economy was the most important for all municipalities.
\end{abstract}

\section{Introduction}

A serious scientific problem is estimation of the environmental effect of economic development and identification of patterns in interrelations between environmental and economic characteristics of ongoing processes. With the proposed approach, we can determine the relationships between parameters of functions and indices of different levels (the economy of regions and its territories of municipalities), estimate the effect of structural shifts in the economy and of changes in the structure of investments by types, examine different variants of resource distribution among sectors, and construct the ones optimal by various criteria.

A great deal of attention to the state of environment has increases interest in identifying factors influencing environmental processes and estimating the impact of economic development on the environment. Initially, an IPAT-based approach was proposed, which made it possible to make an approximate estimation of the impact of population dynamics, the level of development of the country and the technology level. Later, the STIRPAT stochastic model was proposed, which allowed making more accurate estimates and identifying the influence of various factors:

\footnotetext{
*Corresponding author: lelyapotasheva@yandex.ru
} 


$$
E_{I}(t)=A \times P_{i}^{\alpha}(t) \times Y_{i}^{\beta}(t) \times T_{i}^{\gamma}(t)
$$

where: $E(t)$ is the environmental index in question; $Y(t)$ is an indicator characterizing the degree of economic development; $P(t)$ is the population size; $T(t)$ - technological level; $i$ country (region); $t$ is the year; $\alpha, \beta, \gamma$ are constants. Technological level is usually determined by the dimension of specific emissions. The extent of economic development is usually characterized by the gross regional product (GRP) per capita.

The proposed approach was developed, new economic factors were introduced, various countries and regions were investigated, and the theoretical justification of the model was developed. The equation (1) allowed expanding quantity of factors, to enter indicators which can have a noticeable impact on an ecological situation. First of all influence of an urbanization and change of structure of economy - a share of the industry, agriculture, services sector and other industries was investigated.

In the majority of studies on STIRPAT data on the countries and with the different level of development were considered, much less research was done on regional data and very little on municipal data. Panel data were mainly used, a group of countries or regions of one country was considered for a long period of time, usually from the 70s or $80 \mathrm{~s}$.

In connection with the climate changes taking place in recent decades, the focus in researches was made on greenhouse gas emissions, primarily $\mathrm{CO}_{2}$, and significantly fewer studies paid attention to analyzing the dynamics of pollution by various substances of emissions of air and water. It should be noted that the results for different pollutants differ significantly $[1,2,3,4,5,6]$. It was shown that the growth of urbanization leads to a reduction in emissions with a high level of GDP per capita and a large proportion of service industries in GDP [7]. Various indicators were considered, for example, the energy intensity of industry and the proportion of energy consumption obtained from alternative sources [8]. Vehicles have a strong effect on emissions and specific indicators are used to take it into account [9]. Increased urban population density contributes to lower $\mathrm{CO}_{2}$ emissions [10].

Three groups of provinces of China were identified in terms of per capita GRP and panel data research was made for the period of 1997-2012 years. In the sector with the highest GRP per capita defining became the factor relative to energy, in the middle sector it is the impact of urbanization, in the last one - the dynamics of population and GRP per capita [11].

A bit different results turned out for the Canadian regions. The carried-out calculations led to a conclusion that for the Canadian regions the dependence of pollution on GRP is absent, but there is a dependence on population dynamics and used technologies, and also from shares of the industry, a share of export, a share of import, the price of crude oil and other factors [12].

Some researchers have built models based on municipal data. For example, a study of emissions of gases, including nitrogen, showed the importance of the influence of impact of transportation and the need to reduce emissions from it [13]. The paper proposes an approach to assess the impact of structural changes and environmental protection activities.

\section{Materials and Methods}

Economic development mainly leads to quantitative growth, most projects tend to have negative environmental effect, and foundation of new industries increases the load on the environment in one way or another. Other projects - innovative and modifying the structure of the economy, may have the positive effect of reducing the environmental load through modernization of the industrial process, introduction of new technologies, etc. Nature conservation, projects to improve treatment systems reduce the harmful impact on the 
nature with various degrees of effectiveness, which can be estimated by data analysis and identification of equations.

The main advantage of the proposed pollution functions, which are presented in a study is to integrate economic and environmental indices, is that they help explore the dynamics of the environmental efficiency of investments, analyse the effect of changes in the structure of investments and the economy, and take account of the possibility of one factor compensating for another. Pollution functions can be a two- or a three-factor function, based on simple or on integrated environmental indices:

$$
E(t)=F\left(U_{1}(t), U_{2}(t), U_{3}(t), t\right)
$$

where: $E(t)$ is the environmental index in question, $U_{l}(t)$ - factor describing economic development, which, as a rule, tells negatively on the environment (investments in new construction projects, industrial production, etc.), $U_{2}(t)$ - factor describing conservation activities and enhancing the environment (investments in nature protection, current costs of nature protection, etc.), $U_{3}(t)$ - factor reflecting structural changes in the economy, which, as a rule, have positive effect on the environment (investments in the economy, investments in modernization of production facilities, etc.).

With a purpose to view ecological and economic indicators, it was introduced the notion of factor elasticities, which are logarithmic derivatives of pollution functions by factors. Proposed parameters $\varepsilon_{1}$ and $\varepsilon_{2}$ can be defined as elasticities of pollution for a factor, which predetermine its efficiency. They describe the degree of impact of the factors: if industrial production (or another economic index) grows by $1 \%$ the investigated environmental index grows by $\varepsilon_{1} \%$, and if investments in nature protection (or another conservation index) are increased by $1 \%$ it would change by $\varepsilon_{2} \%$, decrease to be more exact, since elasticity $\varepsilon_{2}$ is negative.

One more introduced parameter is the notion of neutral environmental progress, which is related to changes in the pollution level dependent on time or on other factors. Neutral environmental progress is most significantly influenced by structural shifts.

At the first stage of the study, we used the simplest functions:

$$
\begin{gathered}
E(t)=A \times \exp (p \times t) \times U_{1}^{\mu}(t) \times U_{2}^{-p}(t) \\
E(t)=A \times \exp (p \times t) \times U_{1}^{\mu}(t) \times U_{2}^{-p}(t) \times U_{3}^{v}(t)
\end{gathered}
$$

This pollution functions enables very convenient calculations - when its logarithm is found, it becomes linear and has plain environmental meaning. Often, $A(t)=\exp (p \times t)$, where: $p$ is the rate of neutral environmental progress, which characterizes the effect of the factors unaccounted for in the formula, including structural shifts, modernization of production facilities, $\mu \geq 0, \eta \geq 0$. Parameters $\varepsilon_{l}=\mu$ and $\varepsilon_{2}=-\eta$ are factor elasticities. Other variants of the functions are also feasible [14].

The study based on the information available from statistical yearbooks of Republic of Karelia and its territories of municipalities. The most significant emissions of pollutants into the atmosphere in the capital of the Republic of Petrozavodsk and industrial centers (Kostomuksha, Kondopoga and Segezha).

In addition, it was examined the environmental indices descriptive of the state of the environment and the effect of the economy on it - point-source pollutant emissions, polluted effluent discharges to surface waters, water uptake from natural sources, toxic waste production, etc. To solve some problems, in the study, simple indices are processed into integrated ones, which reflect the overall effect of the economy on various characteristics. 
The following indices were considered to assess the economic development - industries production, basic assets, investments and their structure, etc. Calculations for major indices we carried out for both integrated and simple indices. Indices by industries we used in equations with simple indices, emissions from vehicles depend on transport development parameters. The dynamics of environmental parameters is influenced also by nature conservation activities, which are described by the following indices - investments in fixed capital aimed to promote nature conservation and sustainable utilization of natural resources, current costs of nature conservation, etc.

The data for the study have to be comparable, which is a difficult but not an impossible task, and the indices most accurately reflecting the changes that have taken place as well as suitable for building special functions we selected during economic analysis. Therefore, one most often considers cumulative investments - the sum of investments cumulated over 3-5 years, or in some cases (identification of incremental functions) investments over one year are used.

\section{Results}

To roughly estimate the interrelation of indices of the main parameters of pollution functions - factor elasticities and the rate of neutral environmental progress, we analysed data and built various graphs of environmental and economic indices and their correlation. As the result, periods with potentially different behavior of the main characteristics of the process in question were identified, assumptions concerning the type of pollution functions were made, potential limitations on pollution functions parameters were determined.

Figure 1 shows data on Republic of Karelia. One can discern two trends, each roughly described by linear relationship. Before 1998, with a nearly 55\% reduction in GRP atmospheric emissions dropped by $50 \%$, whereas afterwards, when GRP increased two times, emissions decreased - to $30 \%$ of the 1990 level. Much of investment channeled to modernization of production facilities and introduction of more up-to-date technologies. The graph suggests there are two periods differing in characteristics.

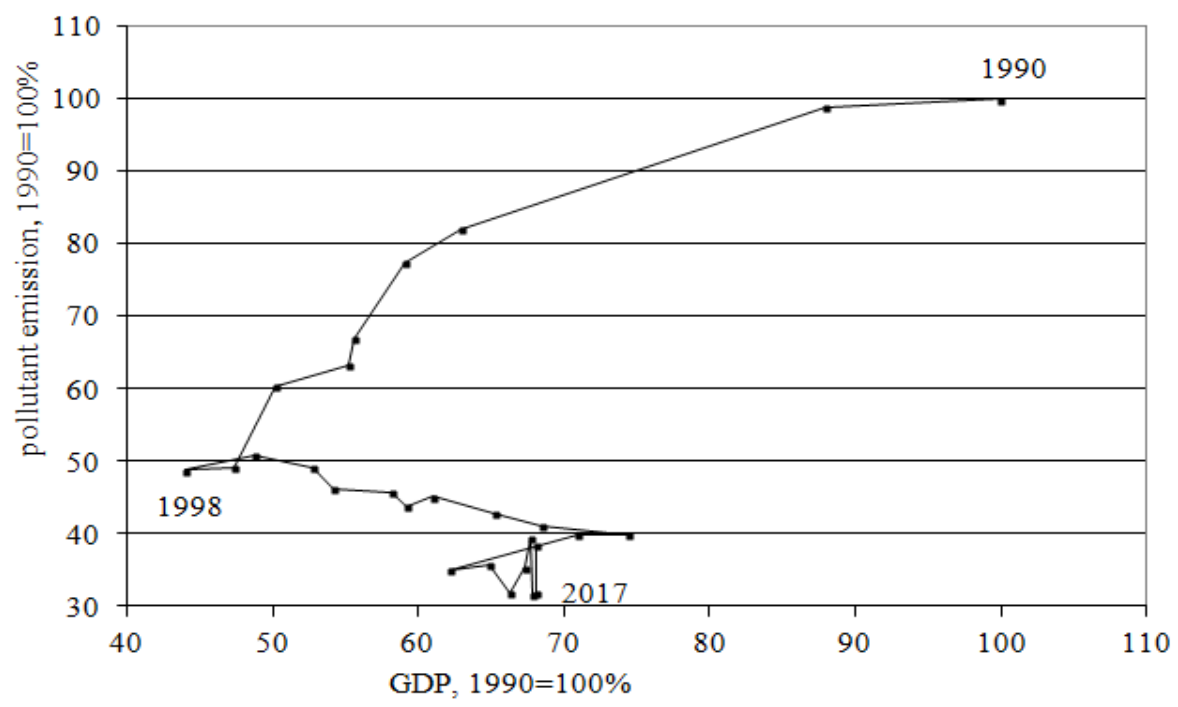

Fig. 1. Connection point-source pollutant emissions $(1990=100 \%)$ and dynamics of Karelian GRP $(1990=100 \%)$.

A similar correlation is demonstrated by data on Petrozavodsk (figure 2). 


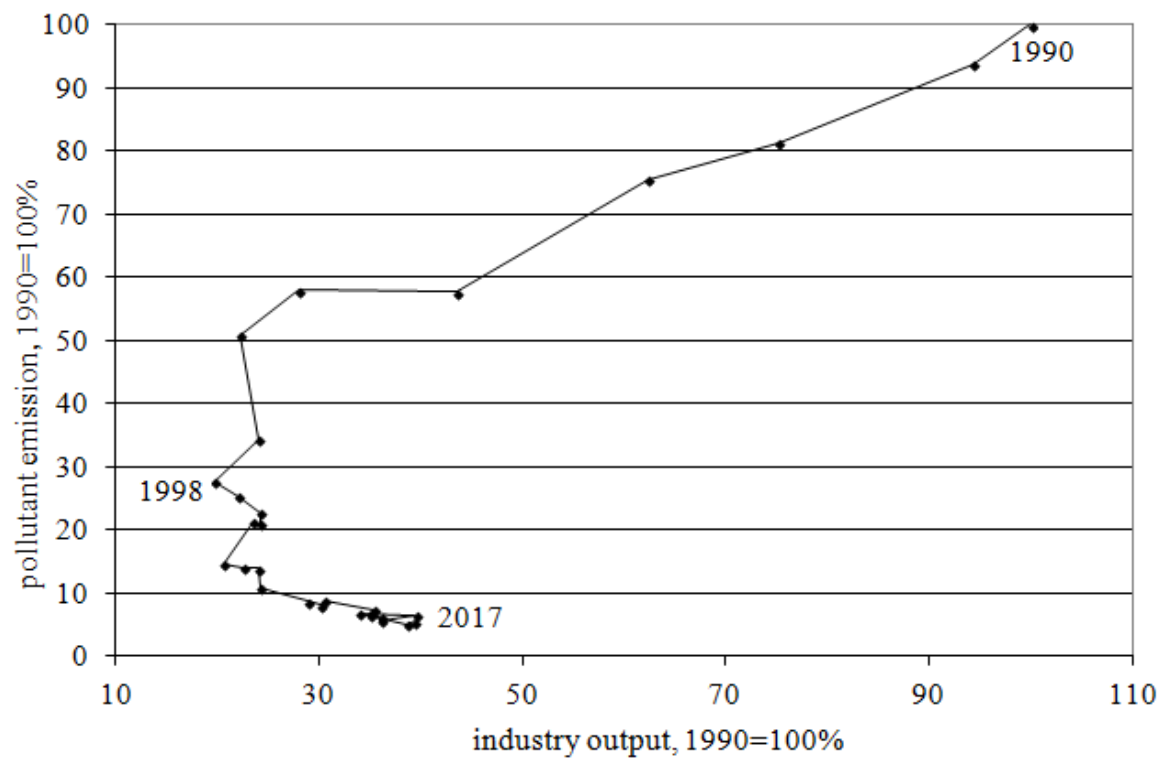

Fig. 2. Connection point-source pollutant emissions $(1990=100 \%)$ and industry output of Petrozavodsk $(1990=100 \%)$.

Before 1998, with a nearly 5-fold reduction in industrial output atmospheric emissions dropped by $75 \%$, whereas afterwards, when industrial output increased two times, emissions decreased - to $5 \%$ of the 1990 level. Much of investment channeled to modernization of production facilities and introduction of more up-to-date technologies, significantly changed the structure of the city's economy.

Figure 3 shows the dynamics of the ratio of emissions of pollutants into the atmosphere and the GRP of Karelia. One can see also that since the late 1990s the growth of GRP has not caused increase in atmospheric emissions.

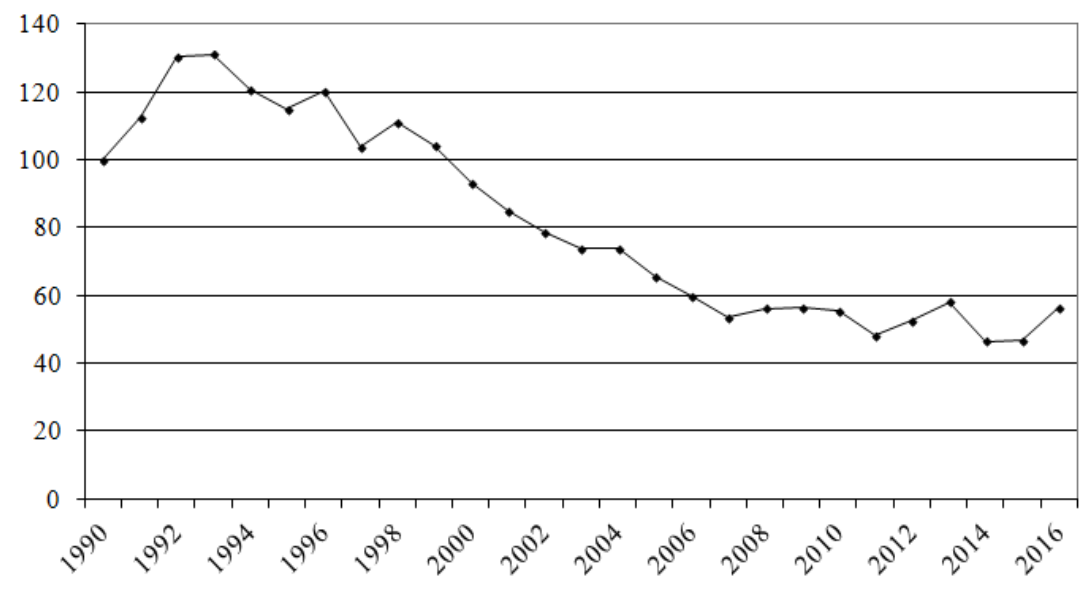

Fig. 3. Dynamics of the ratio of emissions of pollutants into the atmosphere and the GRP of Karelia $(1990=100 \%)$.

Figure 4 shows the dynamics of the ratio of emissions of pollutants into the atmosphere and industry output of Petrozavodsk. 


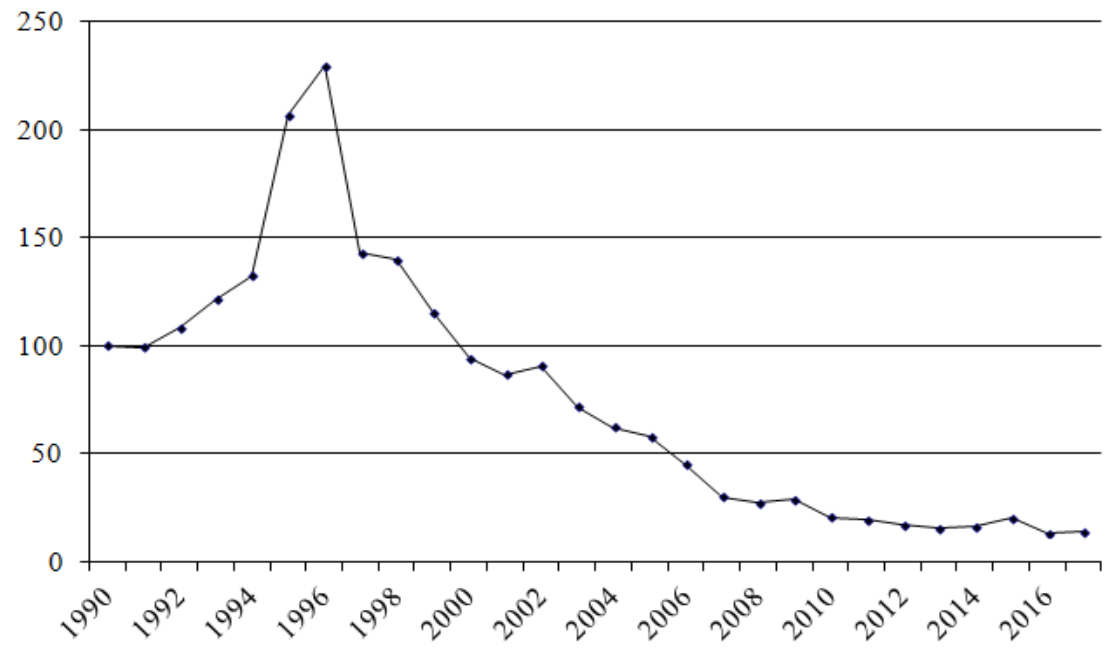

Fig. 4. Dynamics of the ratio of emissions of pollutants into the atmosphere and industry output of Petrozavodsk $(1990=100 \%)$.

Since 1997, the city began to use gas instead of fuel oil for heating, and air emissions of pollutants are significantly reduced. The energy intensity of the Karelian economy is falling, which contributes to reducing emissions of pollutants into the atmosphere [24].

Analysis of data on the Russian regions proved one can build functions with parameters quite stable over certain time periods. Below we report the results of the calculations for Republic of Karelia and Petrozavodsk, through which we determined the effect of changes in the indices on the dynamics of atmospheric emissions. Calculations were carried out for the whole period 1990-2015 and excluding early 1990s. We used data on point-source pollutant emissions, GRP industry output, investments in fixed capital and investments in fixed capital targeted at environment protection.

Calculations were performed for the functions presented above. More realistic is the non-linear function (4), where the elasticity of compensation equals 1 , its environmentaleconomic message is clear, but some problems exist in the use of investments as indices. Calculations using Karelian data resulted in higher values of elasticity for GRP. The result for cumulative investments over 3 years with account of neutral environmental progress was $\mu=0.382$.

Table 1. Results of calculations of pollution functions (3) for emissions of pollutants into the atmosphere in the Republic of Karelia.

\begin{tabular}{|l|c|c|c|c|c|c|}
\hline & $\boldsymbol{\mu}$ & $\boldsymbol{\eta}$ & $\mathbf{p}$ & $\ln \mathbf{A}$ & $\mathbf{R}^{\mathbf{2}}$ & $\mathbf{F}$ \\
\hline $1995-2016$ & $0.382 * *$ & $0.026^{* * *}$ & $-0.032^{* * *}$ & $3.193 * * *$ & 0.89 & 46.4 \\
\hline
\end{tabular}

As a result of calculations for emissions of pollutants into the atmosphere, it was shown that an increase in GRP of $1 \%$ leads to an increase in emissions by $0.38 \%$, an increase in cumulative investments in air protection by $1 \%$ leads to a decrease in emissions by $0.026 \%$, and structural changes in the economy and modernization annual production contributes to reducing emissions by $3.2 \%$.

Coefficient $\eta$ turned out to be close to zero; it ranged between 0.01 and 0.05 when we changed the period covered by calculations and the number of years of investments summed up, and in the presence or absence of neutral environmental progress. Neutral 
environmental progress is negative, being about -0.03; when it is taken into account parameter $\eta$ tends to zero.

Table 2. Results of calculations of pollution functions (4) for emissions of pollutants into the atmosphere in the Petrozavodsk.

\begin{tabular}{|c|c|c|c|c|c|c|c|}
\hline & $\boldsymbol{\mu}$ & $\boldsymbol{\eta}$ & $\boldsymbol{v}$ & $\boldsymbol{p}$ & $\boldsymbol{\operatorname { n n }} \boldsymbol{\boldsymbol { R } ^ { 2 }}$ & $\boldsymbol{F}$ \\
\hline $1998-2015$ & 0 & 0 & $-0.433^{* * *}$ & $-0.049^{* * *}$ & $5.213^{* * *}$ & 0.97 & 210 \\
\hline$* * * \mathrm{p}<0.01$ &
\end{tabular}

From the calculations for the first and second periods, we got high values of the correlation and Fischer's coefficients and likewise for the whole period when investments over 3-5 years were summed up and neutral environmental progress was taken into account.

\section{Discussion}

The STIRPAT model was used for municipalities of southeast part of the USA for assessment of the impact of factors on carbon dioxide emissions [16]. In this case, the model is rather difficult to use, more complex methods and multiple verification of results are necessary. As a result of the research, it turned out that first of all the population size and household incomes affects.

In some papers, several types of pollution were considered, for example, sulfur and nitrogen compounds. Research and development expenditure and other indicators related to technical progress can have a significant impact on emissions $[14,15]$. The effect of demographic indicators on the dynamics of emissions of $\mathrm{SO}_{2}$, nitrogen compounds and solids was also studied, and the correlation dependence of air pollution and population size was established.

The paper proposes a new approach to identifying factors affecting the state of the environment. It is shown that the influence of environmental policy can be assessed using investments in environmental protection.

Emissions of pollutants into the atmosphere in Petrozavodsk have decreased almost 20 times in 28 years due to the modernization of the economy and changes in its structure, reducing the share of industry. Investments in environmental protection had practically no effect on reducing pollutant emissions in Petrozavodsk. Calculations showed that the impact of investments in environmental protection most strongly influenced the environmental performance of industrial centers of Karelia (Kostomuksha, Kondopoga and Segezha) and much less - the environmental performance of the Republic of Karelia as a whole. Investments in environmental protection significantly reduce discharges from most polluting industries (metal processing, pulp-and-paper industry).

\section{Conclusions}

The main advantage of the proposed pollution functions, which integrate economic and environmental indices, is that they help investigate the dynamics of the environmental efficiency of investments, analyse the effect of changes in the structure of investments and the economy. The study made it possible to explain the improvement of ecological indicators with economic growth, to identify the factors leading to the improvement of the environment. Structural changes of economic development are important for Petrozavodsk, and investments in environmental protection are important for industrial centres. The growth of investments in active modernization of economy was the most important for all municipalities. 
The study was carried out with the financial support of the Russian Foundation for Basic Research, grant № 17-02-00449.

\section{References}

1. J. Jia, H. Deng, J. Duan, J. Zhao, Ecological Economics 68, 2818-2824 (2009) https://doi.org/10.1016/j.ecolecon.2009.05.012

2. H. Dai, T. Sun, K. Zhang, W. Guo, Sustainability 7, 782-793 (2015) DOI: 10,3390 / su7010782

3. M. Wang, Y. Che, K. Yang, M. Wang, L. Xiong, Y. Huang, Energy Policy 39, 69816990 (2011) DOI:10.1016/j.enpol.2011.07.041

4. Z. Wang, L. Yang, Journal of Cleaner Production 78, 94-103 (2014) https://doi.org/10.1016/j.jclepro.2014.04.041

5. K. Feng, K. Hubacek, D. Guan, Ecological Economics 69, 145-154 (2009) DOI:10.1016/j.ecolecon.2009.08.007

6. P. Sadorsky, Energy Economics 41, 147-153 (2014) https://doi.org/10.1016/j.eneco.2013.11.007

7. M. Chikaraishi, A. Fujiwara, Shi S.nji Kaneko, P. Poumanyvong, S. Komatsu, A. Kalugin, Technological Forecasting and Social Change 90, 302-317 (2015) http://dx.doi.org/10.1016/j.techfore.2013.12.025

8. B. Liddle, Global Environmental Change 31, 62-73 (2015) http://dx.doi.org/10.1016/j.gloenvcha.2014.10.016

9. B. $\mathrm{Xu}, \quad$ B. Lin, Energy 83, 486-495 http://dx.doi.org/10.1016/j.energy.2015.02.052

10. A. Fremstad, A. Underwood, S. Zahran, Ecoloqical Economics 145(30), 137-145 (2018) DOI: 10.1016/j.ecolecon.2017.08.024

11. Y. Wang, T. Zhao, Ecological Indicators 50, 186-195 (2015) https://doi.org/10.1016/j.ecolind.2015.01.018

12. V. Lantz, Q. Feng, Ecological Economics 57, 229-238 (2006) https://doi.org/10.1016/j.ecolecon.2005.04.006

13. T. Laureti, J. Montero, G. Fernandez-Aviles, Energy Policy 74, 557-568 (2014) https://doi.org/10.1016/j.enpol.2014.06.012

14. P.V. Druzhinin, G.T. Shkiperova, Studies on Russian Economic Development 1(23), 66-72 (2012) DOI: 10.1134/S1075700712010030

15. P.V. Druzhinin, A.P. Shcherbak, S.V. Tishkov, Studies on Russian Economic Development 29(3), 280-287 (2018) DOI: 10.1134/S1075700718030036

16. T. Roberts, Applied Geography 31, 731-739 https://doi.org/10.1016/j.apgeog.2010.06.010

17. M. Mazzanti, A. Montini, Ecological Economics 69, 2457-2467 (2010) https://doi.org/10.1016/j.ecolecon.2010.07.021

18. J. He, Ecological Economics https://doi.org/10.1016/j.ecolecon.2009.10.012 